\title{
Moderate dietary weight loss reduces myocardial triglycerides in obese women
}

\author{
Wolfgang Utz ${ }^{1 *}$, Sven Haufe ${ }^{2,3}$, Stefan Engelii, ${ }^{2,3}$, Martin Pofahl ${ }^{1}$, Julius Traber ${ }^{1}$, Friedrich Luft ${ }^{3}$, Jens Jordan², \\ Jeanette Schulz-Menger ${ }^{1}$ \\ From 15th Annual SCMR Scientific Sessions \\ Orlando, FL, USA. 2-5 February 2012
}

\section{Background}

Excessive myocardial triglyceride (MTG) content in obesity and type 2 diabetes is associated with impaired cardiac function. Previous studies suggest that MTG could be mobilized through lifestyle interventions. We assessed influences of moderate dietary weight loss in non diabetic obese women on MTG content and cardiac function.

\section{Methods}

Non diabetic overweight and obese women were submitted to a six months hypocaloric diet with either fat or carbohydrate restriction. Cardiac structure and function was assessed by magnetic resonance imaging (MRI) and MTG content by proton spectroscopy (MRS) in 35 subjects at baseline and follow-up. Anthropometric and metabolic parameters as well as cardio-respiratory fitness were measured.

\section{Results}

An average weight reduction of $6.0 \pm 3.7 \mathrm{~kg}$ at six month was associated with a relative decrease of MTG of $26 \%$ (from $0.73 \pm 0.30 \%$ at baseline to $0.54 \pm 0.23 \%$ at followup, $\mathrm{p}<0.001$, Figure 1). The response was similar with carbohydrate and fat restriction. Lipid spectrum before (left) and after (right) weight loss in one subject is shown in Figure 2. Diastolic function expressed as ratio of peak filling rate in E- and A-Phase (PFRE/PFRA) was unchanged. Reductions of left atrial size $(21.5 \pm 3.3 \mathrm{~cm} 2$ to $19.8 \pm 3.1 \mathrm{~cm} 2, \mathrm{p}=0.002$ ), the ratio of PFRE and left ventricular lengthening velocity PLV (8.1 \pm 2.4 to $7.3 \pm 2.3$, $\mathrm{p}<0.001)$ and fat free mass $(55.0 \pm 7.1 \mathrm{~kg}$ to $52.5 \pm 6.7 \mathrm{~kg}$,

'Working Group Cardiac MR Medical Faculty, Charité Campus Buch and HELIOS Klinikum Berlin Buch, Berlin, Germany

Full list of author information is available at the end of the article $\mathrm{p}=0.007)$ reflected altered loading conditions after diet, but did not correlate to MTG content.

\section{Conclusions}

Moderate dietary weight loss significantly reduced MTG content in women with uncomplicated obesity. Macronutrient composition of the diet did not significantly affect the extent of MTG reduction.

\section{Funding}

None.

\section{Author details}

'Working Group Cardiac MR Medical Faculty, Charité Campus Buch and HELIOS Klinikum Berlin Buch, Berlin, Germany. Institute of Clinical

Pharmacology, Hannover Medical School, Hannover, Germany. ${ }^{3}$ Experimental

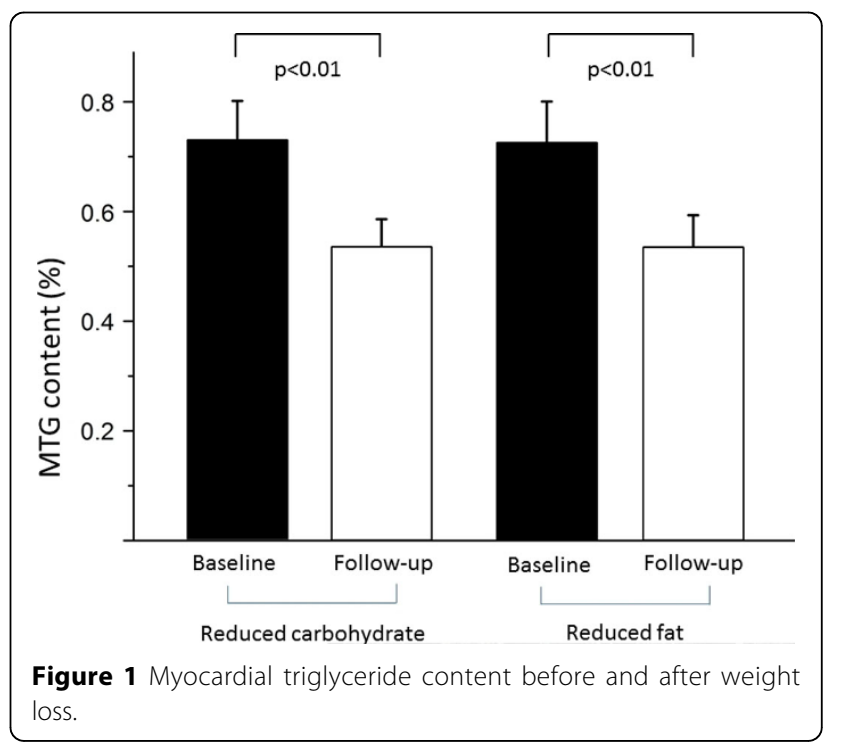

(c) 2012 Utz et al; licensee BioMed Central Ltd. This is an open access article distributed under the terms of the Creative Commons 


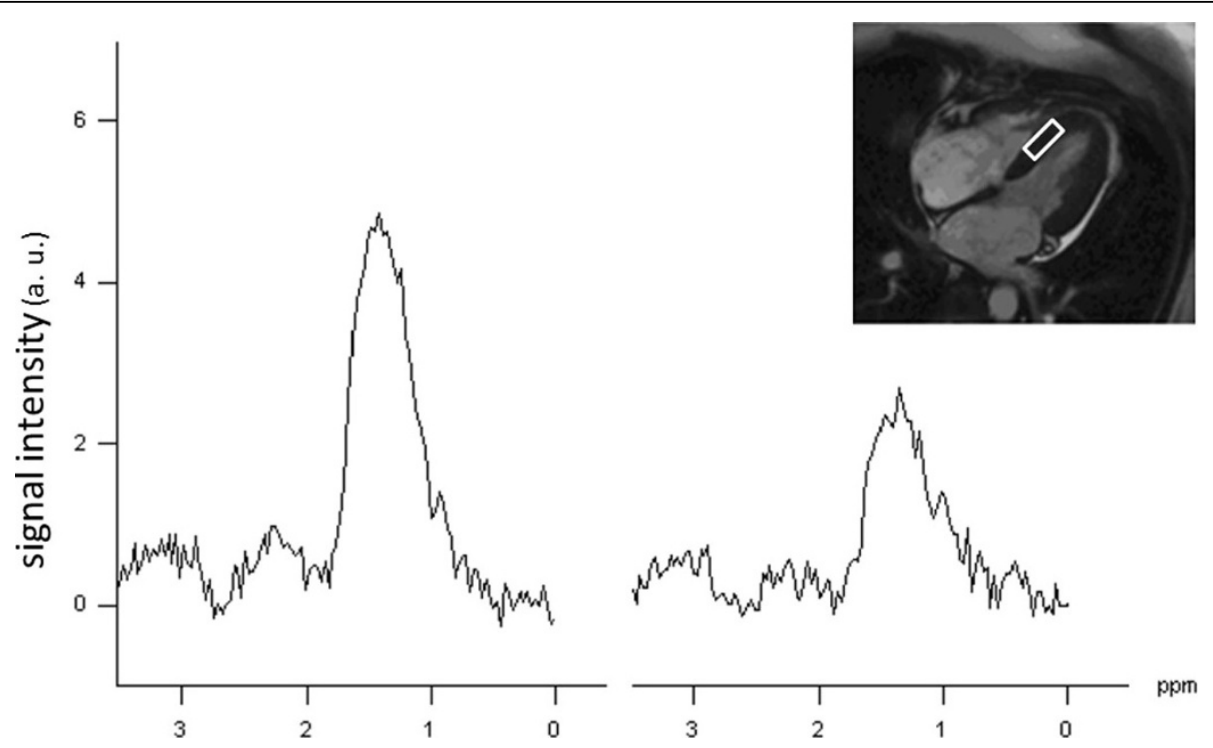

Figure 2 Lipid spectra normalized to water signal in one subject before (left) and after (right) intervention showing reduced MTG at FU (inlet depicts voxel position).

and Clinical Research Center, Charité Medical School and Max Delbrück Center for Molecular Medicine, Berlin, Germany.

Published: 1 February 2012

doi:10.1186/1532-429X-14-S1-P69

Cite this article as: Utz et al: Moderate dietary weight loss reduces myocardial triglycerides in obese women. Journal of Cardiovascular Magnetic Resonance 2012 14(Suppl 1):P69.
Submit your next manuscript to BioMed Central and take full advantage of:

- Convenient online submission

- Thorough peer review

- No space constraints or color figure charges

- Immediate publication on acceptance

- Inclusion in PubMed, CAS, Scopus and Google Scholar

- Research which is freely available for redistribution

Submit your manuscript at www.biomedcentral.com/submit
C Biomed Central 